\title{
Diffusion Weighted/Tensor Imaging, Functional MRI and Perfusion Weighted Imaging in Glioblastoma- Foundations and Future
}

\section{OPEN ACCESS}

Edited by:

Adam M. Sonabend,

Feinberg School of Medicine,

United States

Reviewed by:

Yoshua Esquenazi,

University of Texas Health

Science Center at Houston,

United States

Brad E. Zacharia,

Penn State Milton S. Hershey Medical Center

United States

Pierpaolo Peruzzi,

Brigham and Women's Hospital,

United States

*Correspondence:

Rohan Ramakrishna

ror9068@med.cornell.edu

these authors have contributed equally to this work.

Specialty section: This article was submitted to Neuro-Oncology and Neurosurgical Oncology, a section of the journal Frontiers in Neurology

Received: 25 August 2017 Accepted: 22 November 2017 Published: 22 January 2018

Citation:

Salama GR, Heier LA, Patel $P$

Ramakrishna R, Magge $R$ and Tsiouris AJ (2018) Diffusion Weighted/Tensor Imaging, Functional MRI and Perfusion Weighted Imaging in GlioblastomaFoundations and Future. Front. Neurol. 8:660. doi: 10.3389/fneur.2017.00660

\section{Gayle R. Salama ${ }^{1 \dagger}$, Linda A. Heier ${ }^{1 \dagger}$, Praneil Patel't, Rohan Ramakrishna ${ }^{2 *}$, Rajiv Magge ${ }^{3}$ and Apostolos John Tsiouris ${ }^{1}$}

\begin{abstract}
'Department of Neuroradiology, Weill Cornell Medical College, New York, NY, United States, ${ }^{2}$ Department of Neurological Surgery, Weill Cornell Medical College, New York, NY, United States, ${ }^{3}$ Department of Neurology, Weill Cornell Medical College, New York, NY, United States
\end{abstract}

In this article, we review the basics of diffusion tensor imaging and functional MRI, their current utility in preoperative neurosurgical mapping, and their limitations. We also discuss potential future applications, including implementation of resting state functional MRI. We then discuss perfusion and diffusion-weighted imaging and their application in advanced neuro-oncologic practice. We explain how these modalities can be helpful in guiding surgical biopsies and differentiating recurrent tumor from treatment related changes.

Keywords: diffusion tensor imaging, glioblastoma, functional magnetic resonance imaging, diffusion-weighted imaging, perfusion-weighted imaging

\section{INTRODUCTION}

Advanced imaging is playing an increasingly more important role in the management of patients with neuro-oncologic disease. Its use can help with presurgical risk stratification and delineation of eloquent cortex. While the gold standard remains intraoperative mapping for identification of eloquent brain, preoperative imaging can be of immense value in understanding individual patient anatomy to help make surgery more efficient. In this way, advances in diffusion tensor imaging (DTI) and functional magnetic resonance imaging (fMRI) provide noninvasive means of brain mapping. Other modalities, like transmagnetic stimulation (TMS) are also useful adjuncts and can make intraoperative mapping more efficient. After surgery, advanced imaging can help distinguish between the historically vexing diagnoses of either tumor recurrence or treatment-related change. In this review, we focus on the presurgical utility of DTI and fMRI and then move toward discussing how perfusion and diffusion imaging can more effectively guide patient management in diagnostically challenging situations.

\section{DIFFUSION TENSOR IMAGING}

Diffusion tensor imaging (DTI) has provided the first in vivo visualization of white matter tracts in the brain (1). This fiber tracking technique has become an essential component of a multimodality approach to presurgical intraoperative planning and decision making. It demonstrates morphologic and anatomic information, previously inaccessible to the neurosurgeon without direct electrical stimulation, including demonstration of the corticospinal tract (CST) and arcuate fasciculus, which 
can influence the extent of surgical resection. As asserted by Potgieser et al., "the ultimate goal and major challenge in glioma surgery is to obtain maximal resection while minimizing loss of neurological function," and DTI provides a means to protect eloquent white matter tracts (1).

By measuring the diffusivity of water molecules, a map of the axonal network in the brain is created. Specifically, DTI uses anisotropy, the restriction of random three-dimensional (3D) Brownian motion of water molecules in white matter, to estimate the in vivo axonal direction within a particular voxel $(2,3)$. Tractography pieces together this information from voxel to voxel to model long-range pathways of white matter tracts (4). DTI, developed from diffusion-weighted imaging (DWI), uses magnetic gradients in at least six directions to create a model of diffusion in three dimensions (5). The direction of maximum diffusivity of water molecules coincides with the main white matter fiber orientation. Fractional anisotropy (FA), a unit-less numerical value between 0 and 1, correlates with the degree of directionality of diffusion, with higher FA values corresponding to greater directionality. These FA values can be used to create color-coded tractography maps, with blue corresponding to tracts traveling in the superior-inferior plane, red for tracts in the horizontal plane, and green for tracts in the anterior-posterior plane (Figure 1) $(6,7)$. Another way of visualizing the data is through fiber tracking, which demonstrates neural tracts in 3D. For example, DTI has been used to interrogate pathways, such as the CST (Figures 2 and 4), optic tract, superior longitudinal fasciculus, and arcuate fasciculus (Figure 3) (1, 5, 8-11).

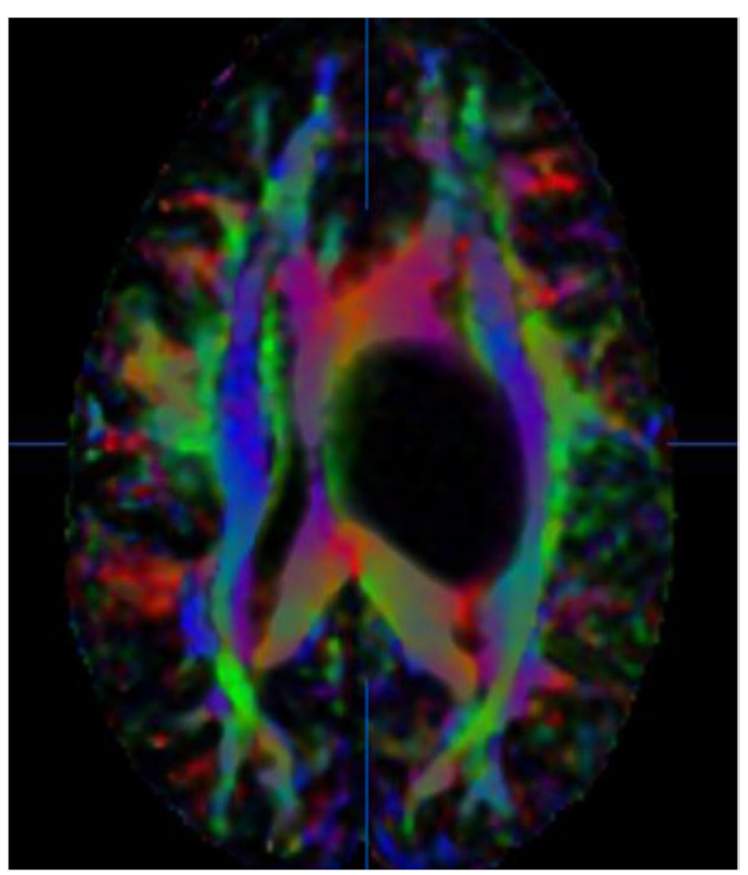

FIGURE 1 | 36-year-old woman with a left thalamic glioblastoma. Fractional anisotropy (FA) color-coded map with tracts coded in blue for the superiorinferior plane, red for the horizontal plane, and green for the anterior-posterior plane. No copyright permissions were required to use these images.
In the presence of tumor, white matter can be displaced, disrupted, edematous, or infiltrated by tumor. DTI can demonstrate the local effects of tumor on white matter integrity. Four patterns have been typically described: (1) normal signal with altered position/direction suggesting tract displacement; (2) decreased but present signal with normal direction and location suggesting vasogenic edema; (3) decreased signal with disruption of fiber tracts suggesting tumor infiltration; and (4) loss of anisotropic signal suggesting tract destruction (5).

Diffusion tensor imaging provides a presurgical and intraoperative tool, that in conjunction with other modalities, enables a safer, more patient-specific procedure (12). Integration of DTI/ fMRI into neurosurgical navigation systems to provide patientspecific guidance will contribute to the efficacy and safety of
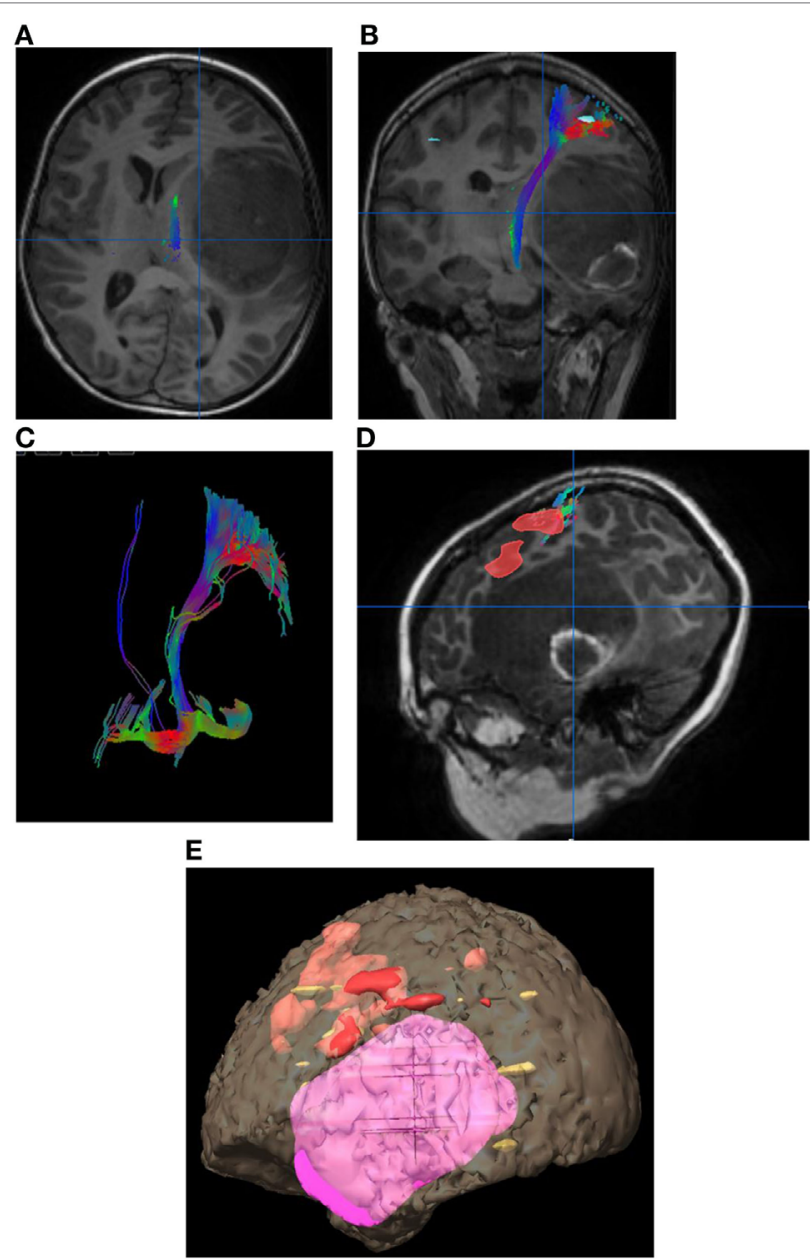

FIGURE 2 | Eight-year-old right-handed boy with left temporal lobe glioblastoma. (A) Tractography in the axial plane demonstrating the left corticospinal tract (CST). (B) Tractography of the left CST in the coronal plane. (C) Three-dimensional fiber tracking of the left CST. (D) Sagittal T1-weighted image with fused language activation colored red demarcating Broca's area, which is elevated by the left temporal lobe tumor. (E) Threedimensional reconstruction with the tumor in pink and task-based functional areas of eloquent language in red, yellow, and orange. No copyright permissions were required to use these images. 
neurosurgical resections, especially in the presence of anatomic distortion (Figure 5) $(13,14)$.

Tractography requires a diffusion model, a fiber-tracking algorithm, and a set of anatomical regions of interest (ROIs). The fibertracking algorithm reconstructs the trajectory of the white matter based on the directional information given by the diffusion model and the anatomical ROIs. The fiber-tracking algorithm may use deterministic, probabilistic, filtered, or global approaches which are all different mathematical analyses of the same DTI pulse sequence. An exact knowledge of white matter tracts is required to identify errors generated by these algorithms (15).

Concordance between DTI tractography and direct electrical stimulation is reportedly high with a sensitivity of $92.6 \%$ and specificity of $93.2 \%(1,16)$. Furthermore, improved outcomes have resulted when preoperative DTI fiber tracking has been performed with a decrease in postoperative deficits from 32.8 to $15.3 \%$ and a longer median survival in high-grade glioma patients of 21.2 months compared to 14.0 months in the control group (17).

Although a promising modality for improved surgical planning and patient safety, DTI is subject to several pitfalls and

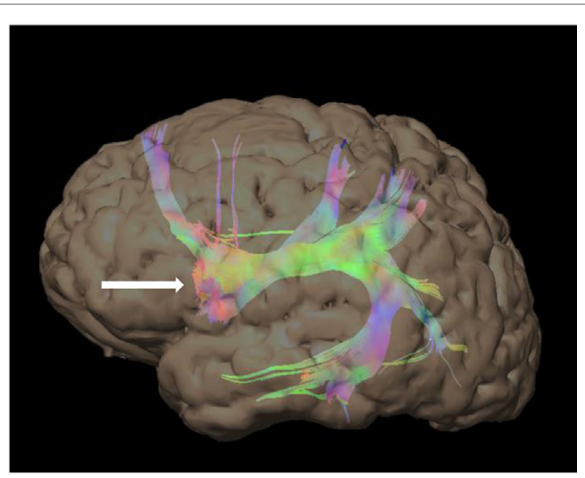

FIGURE 3 | 48-year-old right-handed patient with a right-sided temporal lobe glioma with left hemisphere dominance. Three-dimensional color tractography of the arcuate fasciculus from a task-based functional area consistent with Broca's area (red blob marked with white arrow) viewed from the left. No copyright permissions were required to use these images. limitations. First, the lack of a standard analysis protocol limits reproducibility and accuracy (15). Second, DTI has limited accuracy in the presence of crossing fibers and false tracts may be created. Third, the DTI sequence is very susceptible to inhomogeneity within the magnetic field. This limiting factor is magnified in the intraoperative setting because of increased susceptibility from air-tissue boundaries (1). Fourth, tumor involvement can change the architecture of white matter, so DTI may underestimate the presence of functional white matter tracts in the presence of tumor (18). Fifth, there is a high degree of user discretion required in determining appropriate FA thresholds made more complicated by tumor-related distortion and edema; however, ongoing improvements in software allowing for automatic segmentation can help practitioners separate noise and artifact from real white matter tracts. Finally, brain shift during the course of surgery from positioning, anesthesia, retraction, edema, and CSF leakage can result in loss of spatial congruency between cerebral structures and images, limiting tractography accuracy (19, 20). Since intraoperative parenchymal shift may be up to $15 \mathrm{~mm}$, a recommended safety margin of at least $5-10 \mathrm{~mm}$ should be taken into account when approaching eloquent tracts (19, 21-23). However, such suggestions of "margin" are at best guides; the safest approach is to integrate intraoperative subcortical mapping with navigational data including DTI. Advents in technology including ultrasound guided reorientation of navigational data have emerged, but none are exacting enough to provide the spatial resolution necessary to operate near eloquent white matter tracts.

Many authors feel that DTI is no longer the gold standard for 3 D fiber tracking produced by DWI (24-26). Currently, most DTI sequences utilized for intraoperative mapping use 64 or fewer diffusion directions with only a single shell of diffusion values $\left(b=1,000 \mathrm{~s} / \mathrm{mm}^{2}\right)$ and an approximate 5-6-min acquisition. These technical factors cannot overcome the serious crossing fiber problem. DTI fails to resolve the multiple fiber directionalities per voxel limitation required to visualize smaller white matter tracts or the corticospinal tract in its true entirety (24). Despite the advent of higher order models such as high angular resolution diffusion imaging (HARDI) and diffusion spectrum imaging
A

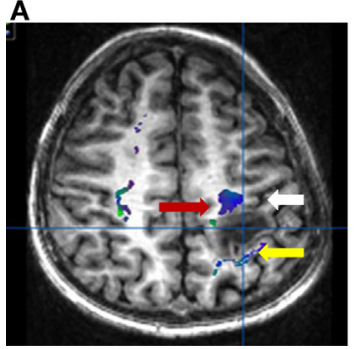

B

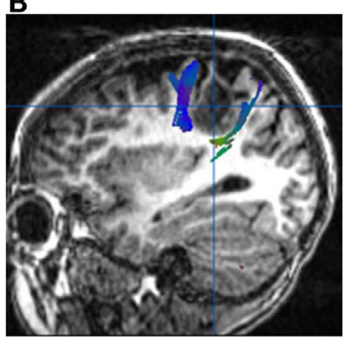

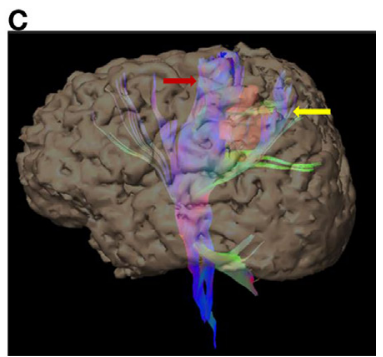

FIGURE 4 | Six-year-old right-handed boy with WHO grade III anaplastic astrocytoma in the subcortical white matter of the left postcentral gyrus. Central sulcus is marked with a white arrow. (A) Axial T1-weighted anatomic image overlaid with directionally color-coded fiber tracking demonstrating the motor (red arrow) and sensory (yellow arrow) corticospinal tracts spread apart by the lesion. (B) Sagittal T1-weighted anatomic image overlaid with directionally color-coded fiber tracking demonstrating the motor (red arrow) and sensory (yellow arrow) corticospinal tracts spread apart by the lesion. (C) Three-dimensional reconstruction with the tumor, colored red, separating the motor (red arrow) and sensory fiber tracts (white arrow). No copyright permissions were required to use these images. 

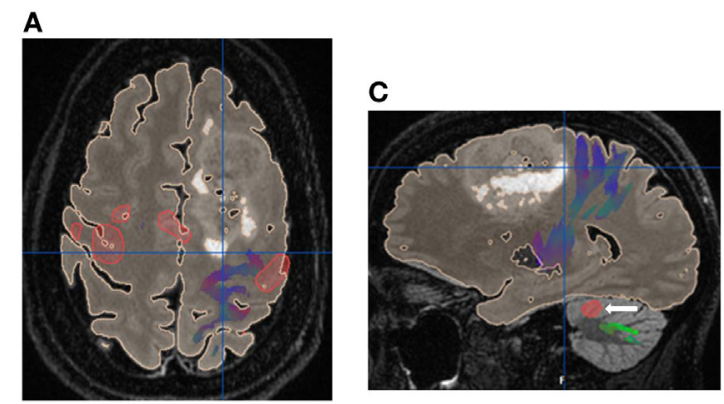

B
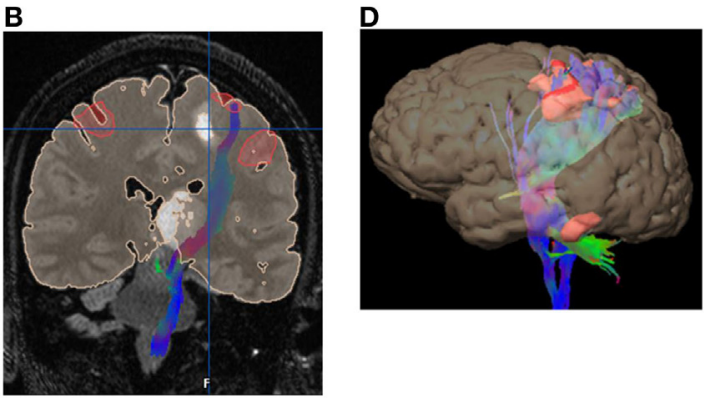

FIGURE 5 | 52 years old with gliomatosis involving the left posterior frontal lobe and left thalamus. Integrated surgical plan with task-based functional motor activation with the associated corticospinal tract fiber tracking (A) Axial image with the eloquent motor cortex in red with the associated left corticospinal tract (CST) fiber tracking (blue) displaced posteriorly by the left frontal lobe mass. (B) Coronal image with the eloquent motor cortex in red with the associated left CST fiber tracking (blue) displaced laterally by the left thalamic mass. (C) Sagittal image with the left CST fiber tracking (blue) displaced posteriorly by the left frontal lobe mass. Note the associated cerebellar activation (white arrow). (D) Three-dimensional reconstruction with eloquent motor cortex in red and directionally color-coded CST fiber tracking. No copyright permissions were required to use these images.

(DSI) which produce more robust and accurate fiber orientation, newer methods have not yet translated well into the clinical arena due to complex post-processing algorithms and long acquisition times $(27,28)$. The first clinical use of advanced fiber tracking methods was a prospective study, which successfully identified language tracts of glioma patients preoperatively and predicted postoperative functional recovery with HARDI q-ball fiber tractography (27).

Recent advances in MR technology including simultaneous multislice echoplanar imaging, multiband excitation, and the use of multiple receivers has accelerated acquisition times permitting DSI to be used clinically. Many of these developments came about due to the work being done on the human connectome project (28). The latest entry to map white matter fibers is diffusional kurtosis imaging (DKI), which is qualitatively comparable to DSI. DKI has a shorter scan time and is therefore a potential clinical favorite (29).

Diffusion tensor imaging is not sufficiently accurate for ideal surgical planning, but it remains to be seen which diffusionweighted method, HARDI, DSI, or DKI, will achieve clinical predominance in the future. All of these methods may overcome current DTI limitations and provide more reproducible and accurate fiber tracking.

\section{FUNCTIONAL MRI}

Functional MRI is a technique to detect eloquent cortex by identifying increased blood oxygen levels in areas of the brain that are activated by task-based paradigms. Optimal presurgical planning requires maximal resection and minimal deficits in areas of eloquent cortex, particularly those contributing to motor and language function. Task-based fMRI correlates with electrophysiology, Wada testing and prediction of functional loss postoperatively (30-33). fMRI indirectly measures neuronal activity by looking at areas of increased blood flow with a specific pulse sequence that uses the ratio of oxyhemoglobin to deoxyhemoglobin as a contrast agent, also known as blood oxygen level-dependent (BOLD) imaging (34).

For surgical mapping, subjects alternate between a passive resting state and an active task-performing state, using the so called "block" paradigm design (Figure 6) (35). An arbitrary statistical threshold determines which voxel is considered "active" and setting the correct threshold is key to limiting noise and optimizing sensitivity (35). Sometimes a scoring system, the Laterality Index is used to choose the dominant hemisphere comparing the total number of active voxels on each side (36). Based on tumor proximity to an eloquent area, approximately $20 \%$ of total neurosurgical cases require fMRI mapping.

Functional MRI motor mapping correlates extremely well with functional areas identified by direct cortical stimulation (DCS) with fMRI having a sensitivity and specificity of 95-100\% (37-39). In contrast, fMRI language mapping is less robust with sensitivity and specificity ranging between $37-91$ and $64-83 \%$, respectively (38). Nevertheless, fMRI is rapidly becoming the study of first resort for determining language dominance in the preoperative setting, as a non-invasive alternative to the Wada test. The Wada test, an intracarotid amobarbital procedure, is currently considered the gold standard. However, it is invasive, may lead to more permanent deficits in vascular compromised patients, has reversible side effects that can temporarily distress patients, must be performed rapidly (3-5 $\mathrm{min}$ ), and can give unreliable results with variations in vascular anatomy. fMRI is cheaper, repeatable, and often less distressing to the patient than Wada testing (35).

Studies comparing the extent of tumor resection with fMRI verses without are limited as most are retrospective. In the few prospective studies that exist the extent of resection in high-grade gliomas, the functional status at 6 months, and progression-free survival (PFS) were improved with DTI functional neuronavigation (17, 39-41).

Limitations to fMRI include the presence of MRI contraindications, such as pacemakers, severe obesity, and claustrophobia, as well as lack of attention and inability to follow task-related commands. The output of task-based fMRI is highly dependent on adequate task performance (42). Additionally, task-based fMRI requires trained personnel and postprocessing, which are difficult to standardize $(42,43)$. Susceptibility artifact from blood products or metallic artifact from surgical plates and dental work may also affect the BOLD sequence used in fMRI. The abnormal vascularity found in and around high-grade gliomas may interfere with the BOLD signal resulting in false-negative results. 

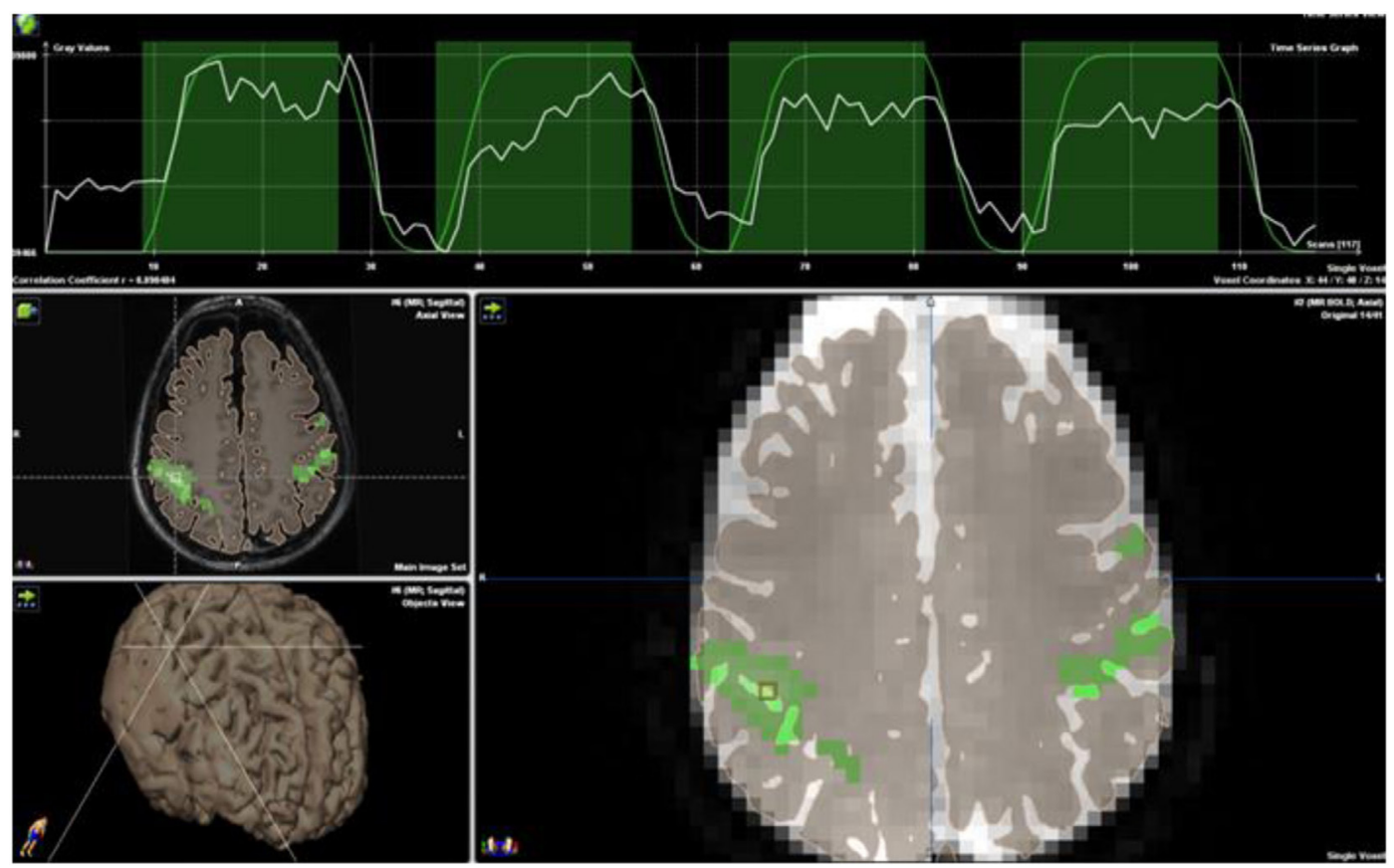

FIGURE 6 | Block paradigm for bilateral finger tapping demonstrating eloquent cortex marked in green. Note the time course strip at the top of the image. Blood oxygen level-dependent activation (white line) is overlaid onto the block paradigms' design (green line) of $18 \mathrm{~s}$ of rest followed by $36 \mathrm{~s}$ of activation, repeated three times for a total paradigm length of $4 \mathrm{~min}$. No copyright permissions were required to use these images.

Likewise, perilesional edema and brain plasticity may contribute to false-positive activations (44).

In patients who are unable to follow commands, an alternative to task-based fMRI is resting-state fMRI (rs-fMRI) (45). Rs-fMRI uses endogenous brain activity, detectable with the BOLD sequence, to identify areas that are interacting at rest to delineate distinct functional networks (46). Rs-fMRI generates correlation maps that are similar to functional maps obtained from task activation (47). Patient participation is not required and fluctuations in BOLD persist under conditions of sleep and anesthesia as well as in the presence of tumors (Figure 7) (48-50). In theory, rs-fMRI can be used in patients of any age and of any cognitive ability. Rs-fMRI is dependent on the selection of a "seed" region in a characteristic location (i.e., the hand-motor area to identify the sensorimotor network) and is thus biased by the technical limitations of the operator (51). Nevertheless, resting-state studies can salvage exams in uncooperative (pediatric or adult) and obtunded patients. While still experimental, increasing numbers of clinical studies proving concordance with task-based fMRI or intraoperative mapping have been published validating the clinical use of rs-fMRI (52-55).

Ultimately, fMRI cannot delineate what exact cortical area is required for a specific function. That said, it can help focus the mapping procedure intraoperatively to improve surgical efficiency. Moreover, it can be helpful in lateralizing language in rightdominant patients. As with DTI though, fMRI requires extensive postprocessing and institutional resources to operationalize on a regular basis. Hospitals without these resources can still perform excellent, safe surgery with DCS. Future directions for fMRI may include its use as an adjunct in planning radiation doses to minimize the effects of radiation toxicity or its use in planning safe trajectories and heat maps for patients who undergo laser interstitial thermal therapy. Finally, more widespread incorporation of ultra-high field magnets ( $7 \mathrm{~T}$ ) will help improve the mesoscopic resolution of fMRI, particularly as it relates to BOLD imaging (56).

\section{MR-PERFUSION AND DWI}

Magnetic resonance perfusion-weighted imaging (PWI) and DWI provide information on tumor physiology that is not accessible with conventional sequences. PWI methods include dynamic susceptibility contrast (DSC) and dynamic contrastenhanced (DCE) perfusion. DSC generates hemodynamic parameters such as relative cerebral blood volume (rCBV) that theoretically reflects microvascular density or area (57). DCE generates a similar parameter, plasma volume (Vp), and K-trans, which is a marker of microvascular permeability or capillary "leakiness." DCE has gained more interest recently due to better spatial resolution and less susceptibility artifacts than DSC, an important attribute in the postoperative setting or in hemorrhagic masses. An alternate sequence first used in the study of ischemia, DWI provides a visual representation of molecular water motion with areas of reduced diffusion [low apparent diffusion coefficient (ADC)] correlating with increased tumor cellularity and other factors (57). In the pretreatment setting, PWI and DWI have been studied as tools to help narrow the differential diagnosis, grade gliomas, guide biopsies, and assess prognosis and potential treatment success. 


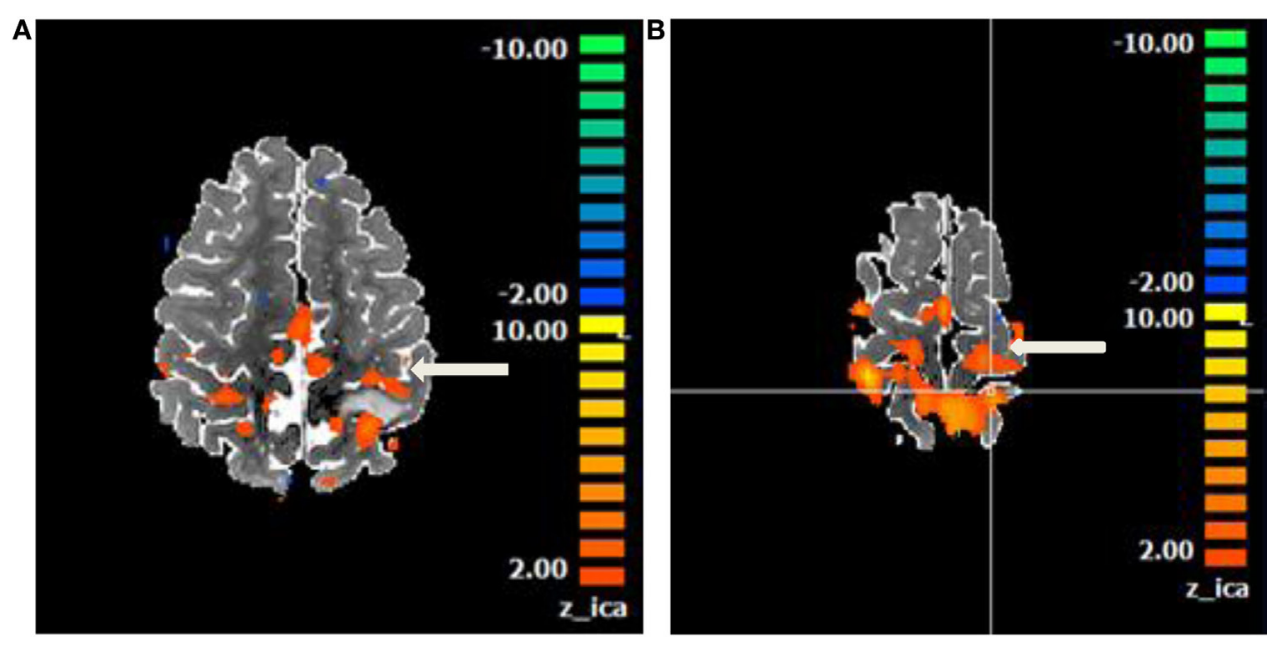

FIGURE 7 | Motor network identified on a resting state functional magnetic resonance imaging in an anesthetized 6-year-old demonstrating eloquent cortex on both sides of a left postcentral gyrus glioma. Central sulcus is marked with white arrow. (A) Axial T2 image with overlaid motor network, in red, separated by T2 hyperintense glioma. (B) Axial T2 image with overlaid motor network on an image slice immediately superior to image (A). No copyright permissions were required to use these images.

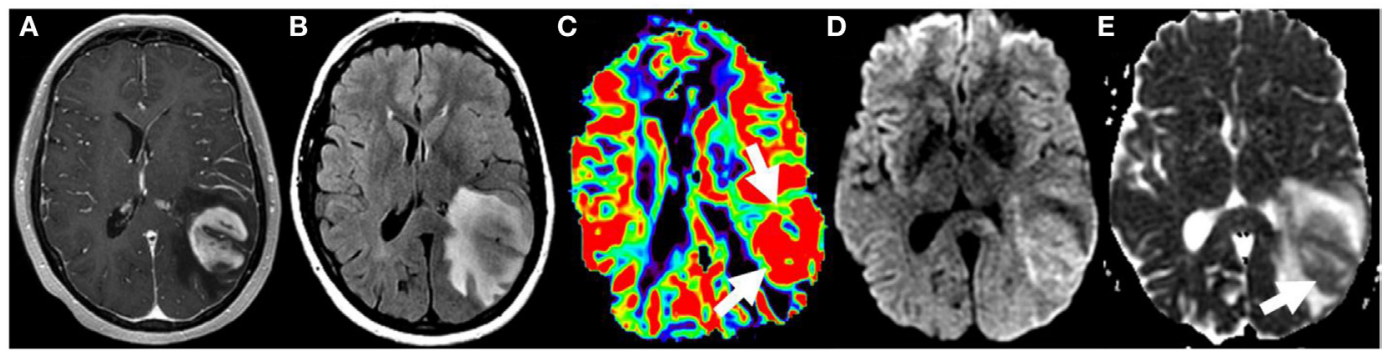

FIGURE 8 | Glioblastoma on initial presentation. T1W postgadolinium (A) and T2W FLAIR (B) magnetic resonance sequences demonstrate a large intra-axial heterogeneously enhancing left parietal mass with extensive surrounding edema and/or infiltrative neoplasm. Elevated relative cerebral blood volume (arrows) is noted on the dynamic susceptibility contrast perfusion map (C) compatible with increased vascular density. The diffusion-weighted imaging

(D) and the corresponding apparent diffusion coefficient map (E) demonstrate heterogeneous restricted water motion (arrow) within this mass most compatible with hypercellularity. No copyright permissions were required to use these images.

As neoplastic and inflammatory conditions with significant differences in management can share conventional imaging findings, PWI and DWI may be of use in narrowing the differential diagnosis. For example, high-grade gliomas demonstrate relatively increased $\mathrm{rCBV}$ in the peritumoral $\mathrm{T} 2$ hyperintense region compared to metastases, which may be related to surrounding infiltrative non-enhancing tumor. In addition, assessment of the DSC signal intensity curve has shown significant differences between high-grade glioma and metastasis in the contrast-enhancing region as well as the peritumoral region (58). Primary CNS lymphoma can also mimic a high-grade glioma but demonstrates lower rCBV and ADC values (59-61). Analysis of the DSC signal intensity curve has demonstrated significant differences between lymphoma, high-grade glioma, and metastasis (62). Certain non-neoplastic pathologies such as tumefactive demyelination similarly demonstrate lower rCBV values (63).

There is a strong correlation between elevated rCBV and highgrade gliomas (Figure 8), with an important exception being low-grade oligodendrogliomas, which can demonstrate relatively elevated values (64-66). Similar correlation has been found with higher K-trans $(67,68)$ and $\mathrm{Vp}(69)$. Lower ADC values have also been reported in higher grade gliomas, related to their increased cellularity $(64,70)$. Low-grade gliomas undergoing transformation can demonstrate increased $\mathrm{rCBV}$ up to 12 months before contrast enhancement is apparent on conventional imaging (71). If this finding were confirmed, PWI would be important to include in surveillance imaging of low-grade gliomas. Starting or changing treatment based on this information and whether early treatment leads to better oncologic outcomes would also need to be debated. However, as PWI and DWI measurements cannot completely obviate the need for tissue sampling at this time, their utility may be greater in the selection of biopsy targets to reduce undersampling (72-74).

The prognostic and predictive capabilities of PWI and DWI in the pretreatment setting have been assessed in several studies related to glioblastoma. Elevated baseline rCBV and K-trans 
values correlated with worse overall survival (OS) after cytotoxic therapy (75-77). Reduced ADC values prior to cytotoxic therapy were associated with reduced OS $(78,79)$. Reduced ADC values were also associated with worse outcomes in a multicenter study of recurrent glioblastoma treated with bevacizumab (80). On the contrary, in treatment-naive glioblastoma, reduced ADC values before antiangiogenic therapy correlated with better outcomes, possibly due to an association with MGMT methylation, highlighting the genetic differences of untreated and recurrent glioblastomas (81). However, the relevance of these findings remains unclear with a recent study suggesting that clinical parameters outperformed advanced imaging metrics in predicting survival at time of diagnosis (82).

In the posttreatment setting, MRI has an essential role with PWI and DWI providing potentially additive information about early therapeutic response with both standard and antiangiogenic therapies and differentiating response from pseudoresponse and true progression from treatment changes. For example, Mangla et al. showed that an increase in $\mathrm{rCBV}$ at 1 month after therapy was predictive of poor 1-year survival (median survival 238 vs. 529 days), whereas change in tumor size was not predictive (83). In a recent meta-analysis, Choi et al. qualitatively reviewed 13 studies and pooled-hazard ratios with $\mathrm{rCBV}$ as the marker for responders and non-responders, concluding that PWI could be considered as a predictive or prognostic biomarker in patients treated with a bevacizumab-based regimen (84). PWI may therefore potentially overcome the limitation of pseudoresponse on conventional postcontrast imaging after antiangiogenic therapy. PWI (and DWI) may additionally help to increase sensitivity and specificity for non-enhancing tumor, given the non-specificity of T2 changes after bevacizumab treatment $(85,86)$.

Diffusion-weighted imaging-derived metrics have similarly shown prognostic potential in the posttreatment setting. For example, Rahman et al. evaluated changes in ADC between baseline and posttreatment exams in recurrent glioblastoma patients on bevacizumab alone or in combination with other chemotherapies. Using histogram analysis, which better characterizes the distribution of values within the area of concern, ADC parameters from baseline and 3- to 6-week posttreatment exams stratified overall and PFS (87). The timing of evaluation appears to have an impact as noted in a study of 37 glioblastoma patients treated with standard therapy followed by adjuvant temozolomide and an antiangiogenic drug. Changes in diffusion parameters were assessed pre-, mid-, and postradiation therapy and correlated with 6-month PFS. Changes in ADC from mid- to postradiation were more significant than other time points, a notable finding as a mid-therapy exam is not typically performed (88).

Perfusion-weighted imaging has also shown promise in helping to differentiate tumor from radiation necrosis or pseudoprogression (Figure 9). A recent meta-analysis calculated pooled

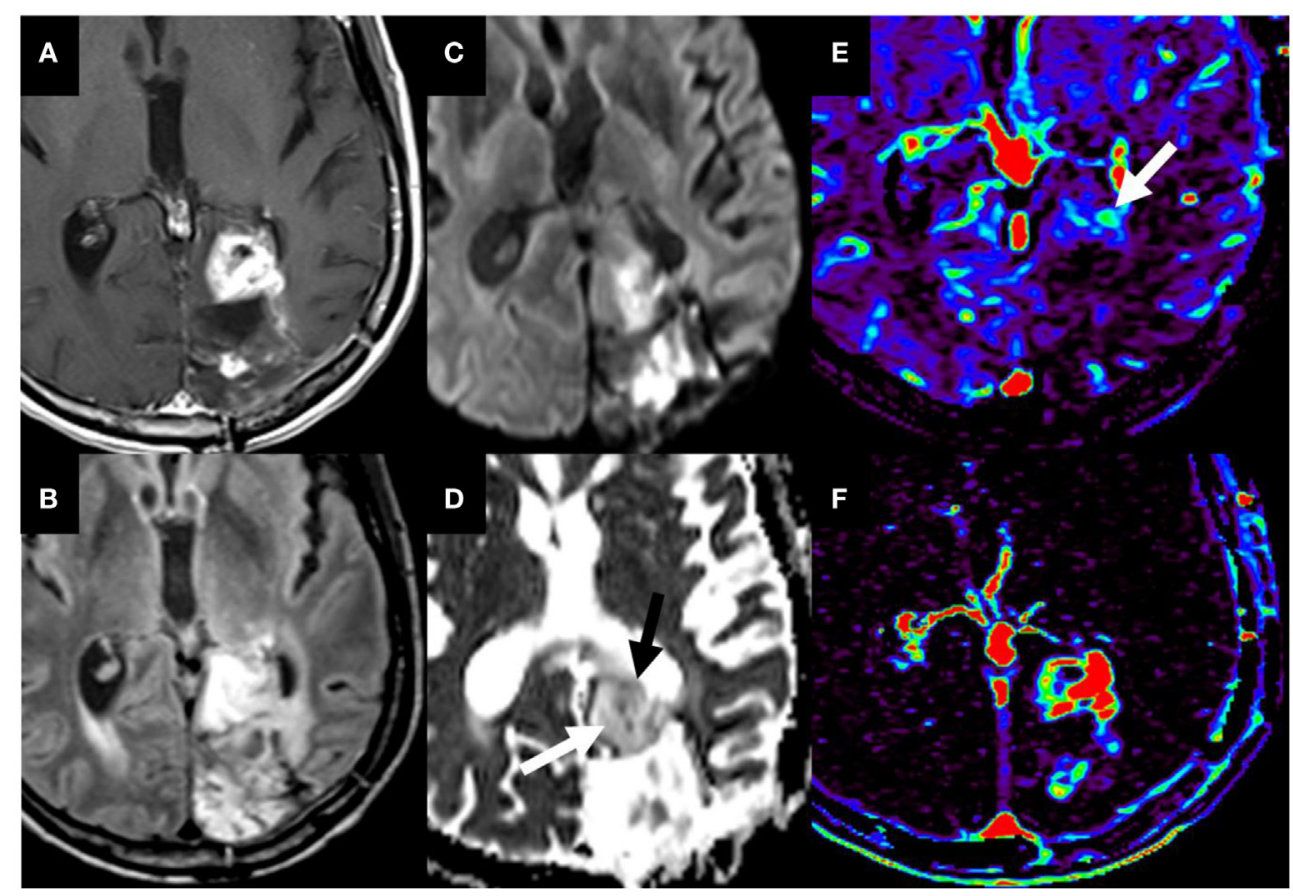

FIGURE 9 | T1W postgadolinium (A) and T2W FLAIR (B) magnetic resonance (MR) sequences demonstrate a region of heterogeneous mass-like enhancement at the anterior border a glioblastoma resection cavity in the left occipital lobe that had progressed since the prior study. Diffusion-weighted imaging (C) and the corresponding ADC map (D) demonstrate predominately increased water motion suggesting necrosis [(D), white arrow]. The dynamic susceptibility contrast maps demonstrate predominately decreased microvascularity on the Vp map (E) with markedly increased permeability on the K-trans map (F). However, there is a smaller internal region of restricted diffusion [(D), black arrow] and increased $V p[(\mathbf{E})$, white arrow]. The combination of these imaging findings, diffusion and perfusion metrics are most compatible with pseudoprogression/treatment changes with a smaller internal region of recurrent tumor. These findings were confirmed on pathology. No copyright permissions were required to use these images. 
sensitivities and specificities of $90 \%$ and $88 \%$ and $89 \%$ and $85 \%$ for identifying recurrent tumor with DSC and DCE, respectively (89). The most commonly evaluated DSC perfusion parameter has been $\mathrm{rCBV}$ with consistent differences shown between tumor and treatment change (90-93). Exceptions include Song et al. who found a difference using ADC but not $\mathrm{rCBV}$ (94) and Kong et al. who found a difference only in the MGMT methylated group (95). Both quantitative and semiquantitative DCE approaches have been increasingly evaluated in the literature and have demonstrated success in separating tumor and treatment change. For example, Thomas et al. evaluated the 90th histogram percentile of normalized Vp (96) and Suh et al. evaluated parameters derived from the area under the time-signal intensity curve with similar accuracy (97). However, currently there is significant variability in the optimal reported perfusion metric thresholds across institutions and PWI acquisition parameters and analytic methods have not been standardized. DWI has also been evaluated in the posttreatment setting with several studies demonstrating significantly lower ADC values in tumor when compared to treatment changes, most likely attributable to the higher cellularity of tumor (98-100).

However, regardless of the technique employed, an admixture of tumor and treatment change is routinely observed on pathology, which can speciously skew quantitative analyses. Thus, there has been investigation of multiparameteric approaches to improve sensitivity and specificity. For example, a combination approach of DWI with either DSC or DCE demonstrated improved predictive accuracy compared to any single parameter in several studies (91, 92, 101). On the contrary, Prager et al. found a combined DSC and DWI model was not significantly better than rCBV alone (93). While beyond the scope of this review, it should be noted that the advanced imaging toolbox also includes PET and MR spectroscopy, which can further aid in a multiparametric approach.

\section{CONCLUSION}

Advanced imaging has an ever increasing role to play in the management of patients with gliomas. Preoperatively, imaging adjuncts like DTI and fMRI can facilitate more efficient surgical mapping procedures and even help determine whether

\section{REFERENCES}

1. Potgieser AR, Wagemakers M, van Hulzen AL, de Jong BM, Hoving EW, Groen RJ. The role of diffusion tensor imaging in brain tumor surgery: a review of the literature. Clin Neurol Neurosurg (2014) 124:51-8. doi:10.1016/j. clineuro.2014.06.009

2. Stejskal EO, Tanner JE. Spin diffusion measurements: spin echoes in the presence of a time-dependent field gradient. J Chem Phys (1965) 42(1):288. doi:10.1063/1.1695690

3. Einstein A. The motion of elements suspended in static liquids as claimed in the molecular kinetic theory of heat. Ann Phys (1905) 17(8):549-60. doi:10.1002/andp.19053220806

4. Lazar M. Mapping brain anatomical connectivity using white matter tractography. NMR Biomed (2010) 23(7):821-35. doi:10.1002/nbm.1579

5. Jellison BJ, Field AS, Medow J, Lazar M, Salamat MS, Alexander AL. Diffusion tensor imaging of cerebral white matter: a pictorial review of physics, fiber intraoperative mapping is necessary in some instances. Future work related to DTI showed focus on making it more accurate and user-independent; this is of particular import in gliomas where tissue edema and destruction can alter white matter pathways in unpredictable ways. Future directions for fMRI may include its use as an adjunct in planning radiation doses to minimize the effects of radiation toxicity or its use in planning safe trajectories and heat maps for patients who undergo laser interstitial thermal therapy.

Despite the strengths of anatomic imaging, there is a need for supplementation with other imaging modalities to better guide treatment. Both PWI and DWI are particularly helpful in biopsy target guidance and in distinguishing recurrent tumor from posttreatment changes. PWI produces more robust parameters than DWI, accounting for greater clinical and research interest. Among PWI techniques, DCE has gained more interest recently given its potential advantages over DSC, particularly in the postoperative setting, and is the preferred technique for tumor surveillance at our institution. Though outside the scope of this article, spectroscopy and positron emission tomography can also be of immense value in resolving diagnostic questions and should be used collaboratively as circumstances require. Either alone or in combination, these advanced imaging tools may eventually provide additional prognostic and molecular information especially given the recent data on molecular heterogeneity between contrast enhancing and non-contrast enhancing disease (102). The potential utility of PWI and DWI will also likely continue to expand as use of novel treatments such as immunotherapy, which can also result in pseudoprogression, become more widely adopted. However, there remains significant variability in the optimal reported quantitative metric thresholds across institutions and neither the RANO criteria for conventional therapies nor the iRANO criteria for immunotherapies have incorporated these techniques to date. Continued research efforts and standardization of acquisition parameters and analytic methods possibly with automation are required to arrive at the most effective approach that can be applied across institutions.

\section{AUTHOR CONTRIBUTIONS}

GS, LH, PP, RR, RM, and AT have all contributed to this article. tract anatomy, and tumor imaging patterns. AJNR Am J Neuroradiol (2004) 25(3):356-69.

6. Misaki T, Beppu T, Inoue T, Ogasawara K, Ogawa A, Kabasawa H. Use of fractional anisotropy value by diffusion tensor MRI for preoperative diagnosis of astrocytic tumors: case report. J Neurooncol (2004) 70(3):343-8. doi:10.1007/ s11060-004-6594-y

7. Douek P, Turner R, Pekar J, Patronas N, Le Bihan D. MR color mapping of myelin fiber orientation. J Comput Assist Tomogr (1991) 15(6):923-9. doi:10.1097/00004728-199111000-00003

8. Berman JI, Berger MS, Mukherjee P, Henry RG. Diffusion-tensor imagingguided tracking of fibers of the pyramidal tract combined with intraoperative cortical stimulation mapping in patients with gliomas. J Neurosurg (2004) 101(1):66-72. doi:10.3171/jns.2004.101.1.0066

9. Catani M, Jones DK, Donato R, Ffytche DH. Occipito-temporal connections in the human brain. Brain (2003) 126(Pt 9):2093-107. doi:10.1093/brain/ awg203 
10. Holodny AI, Watts R, Korneinko VN, Pronin IN, Zhukovskiy ME, Gor DM, et al. Diffusion tensor tractography of the motor white matter tracts in man: current controversies and future directions. Ann N Y Acad Sci (2005) 1064:88-97. doi:10.1196/annals.1340.016

11. Ng WH, Mukhida $\mathrm{K}$, Rutka JT. Image guidance and neuromonitoring in neurosurgery. Childs Nerv Syst (2010) 26(4):491-502. doi:10.1007/ s00381-010-1083-4

12. Romano A, Ferrante M, Cipriani V, Fasoli F, Ferrante L, D’Andrea G, et al. Role of magnetic resonance tractography in the preoperative planning and intraoperative assessment of patients with intra-axial brain tumours. Radiol Med (2007) 112(6):906-20. doi:10.1007/s11547-007-0181-1

13. Dimou S, Battisti RA, Hermens DF, Lagopoulos J. A systematic review of functional magnetic resonance imaging and diffusion tensor imaging modalities used in presurgical planning of brain tumour resection. Neurosurg Rev (2013) 36(2):205-14. doi:10.1007/s10143-012-0436-8

14. Rasmussen IA Jr, Lindseth F, Rygh OM, Berntsen EM, Selbekk T, Xu J, et al. Functional neuronavigation combined with intra-operative 3D ultrasound: initial experiences during surgical resections close to eloquent brain areas and future directions in automatic brain shift compensation of preoperative data. Acta Neurochir (2007) 149(4):365-78. doi:10.1007/s00701006-1110-0

15. Pujol S, Wells W, Pierpaoli C, Brun C, Gee J, Cheng G, et al. The DTI challenge: toward standardized evaluation of diffusion tensor imaging tractography for neurosurgery. J Neuroimaging (2015) 25(6):875-82. doi:10.1111/jon.12283

16. Zhu FP, Wu JS, Song YY, Yao CJ, Zhuang DX, Xu G, et al. Clinical application of motor pathway mapping using diffusion tensor imaging tractography and intraoperative direct subcortical stimulation in cerebral glioma surgery: a prospective cohort study. Neurosurgery (2012) 71(6):1170-83. doi:10.1227/ NEU.0b013e318271bc61

17. Wu JS, Zhou LF, Tang WJ, Mao Y, Hu J, Song YY, et al. Clinical evaluation and follow-up outcome of diffusion tensor imaging-based functional neuronavigation: a prospective, controlled study in patients with gliomas involving pyramidal tracts. Neurosurgery (2007) 61(5):935-48. doi:10.1227/01. neu.0000303189.80049.ab

18. Spena G, Nava A, Cassini F, Pepoli A, Bruno M, D’Agata F, et al. Preoperative and intraoperative brain mapping for the resection of eloquent-area tumors. A prospective analysis of methodology, correlation, and usefulness based on clinical outcomes. Acta Neurochir (Wien) (2010) 152(11):1835-46. doi:10.1007/s00701-010-0764-9

19. Nimsky C, Ganslandt O, Hastreiter P, Wang R, Benner T, Sorensen AG, et al. Preoperative and intraoperative diffusion tensor imaging-based fiber tracking in glioma surgery. Neurosurgery (2005) 56(1):130-7. doi:10.1227/01. NEU.0000144842.18771.30

20. Nauta HJW, Bonnen JG. Problem of intraoperative anatomical shift in imageguided surgery. P Soc Photo Opt Ins (1998) 3262:229-33.

21. Nimsky C, Ganslandt O, Fahlbusch R. Implementation of fiber tract navigation. Neurosurgery (2006) 58(4 Suppl 2):ONS-292-303.

22. Nimsky C, Ganslandt O, Hastreiter P, Wang R, Benner T, Sorensen AG, et al. Intraoperative diffusion-tensor MR imaging: shifting of white matter tracts during neurosurgical procedures - initial experience. Radiology (2005) 234(1):218-25. doi:10.1148/radiol.2341031984

23. Nimsky C, Ganslandt O, Merhof D, Sorensen AG, Fahlbusch R. Intraoperative visualization of the pyramidal tract by diffusion-tensorimaging-based fiber tracking. Neuroimage (2006) 30(4):1219-29. doi:10.1016/j.neuroimage.2005.11.001

24. Farquharson S, Tournier JD, Calamante F, Fabinyi G, Schneider-Kolsky M, Jackson GD, et al. White matter fiber tractography: why we need to move beyond DTI. J Neurosurg (2013) 118(6):1367-77. doi:10.3171/2013.2.JNS121294

25. Young RJ, Tan ET, Peck KK, Jenabi M, Karimi S, Brennan N, et al. Comparison of compressed sensing diffusion spectrum imaging and diffusion tensor imaging in patients with intracranial masses. Magn Reson Imaging (2017) 36:24-31. doi:10.1016/j.mri.2016.10.001

26. Yeh FC, Verstynen TD. Converting multi-shell and diffusion spectrum imaging to high angular resolution diffusion imaging. Front Neurosci (2016) 10:418. doi:10.3389/fnins.2016.00418

27. Caverzasi E, Hervey-Jumper SL, Jordan KM, Lobach IV, Li J, Panara V, et al. Identifying preoperative language tracts and predicting postoperative functional recovery using HARDI q-ball fiber tractography in patients with gliomas. J Neurosurg (2016) 125(1):33-45. doi:10.3171/2015.6.JNS142203
28. Sotiropoulos SN, Jbabdi S, Xu J, Andersson JL, Moeller S, Auerbach EJ, et al. Advances in diffusion MRI acquisition and processing in the Human Connectome Project. Neuroimage (2013) 80:125-43. doi:10.1016/j. neuroimage.2013.05.057

29. Glenn GR, Kuo LW, Chao YP, Lee CY, Helpern JA, Jensen JH. Mapping the orientation of white matter fiber bundles: a comparative study of diffusion tensor imaging, diffusional kurtosis imaging, and diffusion spectrum imaging. AJNR Am J Neuroradiol (2016) 37(7):1216-22. doi:10.3174/ajnr.A4714

30. Sanai N, Mirzadeh Z, Berger MS. Functional outcome after language mapping for glioma resection. AJNR Am J Neuroradiol (2008) 358(1):18-27.

31. Vlieger EJ, Majoie CB, Leenstra S, Den Heeten GJ. Functional magnetic resonance imaging for neurosurgical planning in neurooncology. Eur Radiol (2004) 14(7):1143-53. doi:10.1007/s00330-004-2328-y

32. Adcock JE, Wise RG, Oxbury JM, Oxbury SM, Matthews PM. Quantitative fMRI assessment of the differences in lateralization of language-related brain activation in patients with temporal lobe epilepsy. Neuroimage (2003) 18(2):423-38. doi:10.1016/S1053-8119(02)00013-7

33. Haberg A, Kvistad KA, Unsgard G, Haraldseth O. Preoperative blood oxygen level-dependent functional magnetic resonance imaging in patients with primary brain tumors: clinical application and outcome. Neurosurgery (2004) 54(4):902-14. doi:10.1227/01.NEU.0000114510.05922.F8

34. Matthews PM, Honey GD, Bullmore ET. Applications of fMRI in translational medicine and clinical practice. Nat Rev Neurosci (2006) 7(9):732-44. doi:10.1038/nrn1929

35. Bauer PR, Reitsma JB, Houweling BM, Ferrier CH, Ramsey NF. Can fMRI safely replace the Wada test for preoperative assessment of language lateralisation? A meta-analysis and systematic review. J Neurol Neurosurg Psychiatry (2014) 85(5):581-8. doi:10.1136/jnnp-2013-305659

36. Seghier ML. Laterality index in functional MRI: methodological issues. Magn Reson Imaging (2008) 26(5):594-601. doi:10.1016/j.mri.2007.10.010

37. Tate MC, Herbet G, Moritz-Gasser S, Tate JE, Duffau H. Probabilistic map of critical functional regions of the human cerebral cortex: Broca's area revisited. Brain (2014) 137(Pt 10):2773-82. doi:10.1093/brain/awu168

38. Trinh VT, Fahim DK, Maldaun MV, Shah K, McCutcheon IE, Rao G, et al. Impact of preoperative functional magnetic resonance imaging during awake craniotomy procedures for intraoperative guidance and complication avoidance. Stereotact Funct Neurosurg (2014) 92(5):315-22. doi:10.1159/000365224

39. Ottenhausen M, Krieg SM, Meyer B, Ringel F. Functional preoperative and intraoperative mapping and monitoring: increasing safety and efficacy in glioma surgery. Neurosurg Focus (2015) 38(1):E3. doi:10.3171/2014.10. FOCUS14611

40. Bailey PD, Zaca D, Basha MM, Agarwal S, Gujar SK, Sair HI, et al. Presurgical fMRI and DTI for the prediction of perioperative motor and language deficits in primary or metastatic brain lesions. J Neuroimaging (2015) 25(5):776-84. doi:10.1111/jon.12273

41. Barbosa BJ, Mariano ED, Batista CM, Marie SK, Teixeira MJ, Pereira CU, et al. Intraoperative assistive technologies and extent of resection in glioma surgery: a systematic review of prospective controlled studies. Neurosurg Rev (2015) 38(2):217-26. doi:10.1007/s10143-014-0592-0

42. Bookheimer S. Pre-surgical language mapping with functional magnetic resonance imaging. Neuropsychol Rev (2007) 17(2):145-55. doi:10.1007/ s11065-007-9026-X

43. Tharin S, Golby A. Functional brain mapping and its applications to neurosurgery. Neurosurgery (2007) 60(4 Suppl 2):185-201.

44. Krivosheya D, Prabhu SS, Weinberg JS, Sawaya R. Technical principles in glioma surgery and preoperative considerations. J Neurooncol (2016) 130(2):243-52. doi:10.1007/s11060-016-2171-4

45. Lee MH, Smyser CD, Shimony JS. Resting-state fMRI: a review of methods and clinical applications. AJNR Am J Neuroradiol (2013) 34(10):1866-72. doi:10.3174/ajnr.A3263

46. Fox MD, Raichle ME. Spontaneous fluctuations in brain activity observed with functional magnetic resonance imaging. Nat Rev Neurosci (2007) 8(9):700-11. doi:10.1038/nrn2201

47. Smith SM, Fox PT, Miller KL, Glahn DC, Fox PM, Mackay CE, et al. Correspondence of the brain's functional architecture during activation and rest. Proc Natl Acad Sci U S A (2009) 106(31):13040-5. doi:10.1073/ pnas.0905267106

48. Fukunaga M, Horovitz SG, van Gelderen P, de Zwart JA, Jansma JM, Ikonomidou VN, et al. Large-amplitude, spatially correlated fluctuations 
in BOLD fMRI signals during extended rest and early sleep stages. Magn Reson Imaging (2006) 24(8):979-92. doi:10.1016/j.mri.2006.04.018

49. Zhang D, Johnston JM, Fox MD, Leuthardt EC, Grubb RL, Chicoine MR, et al. Preoperative sensorimotor mapping in brain tumor patients using spontaneous fluctuations in neuronal activity imaged with functional magnetic resonance imaging: initial experience. Neurosurgery (2009) 65(6 Suppl):226-36. doi:10.1227/01.NEU.0000350868.95634.CA

50. Breshears JD, Gaona CM, Roland JL, Sharma M, Bundy DT, Shimony JS, et al. Mapping sensorimotor cortex with slow cortical potential resting-state networks while awake and under anesthesia. Neurosurgery (2012) 71(2):305-16. doi:10.1227/NEU.0b013e318258e5d1

51. Mitchell TJ, Hacker CD, Breshears JD, Szrama NP, Sharma M, Bundy DT, et al. A novel data-driven approach to preoperative mapping of functional cortex using resting-state functional magnetic resonance imaging. Neurosurgery (2013) 73(6):969-82. doi:10.1227/NEU.0000000000000141

52. Hou BL, Bhatia S, Carpenter JS. Quantitative comparisons on hand motor functional areas determined by resting state and task BOLD fMRI and anatomical MRI for pre-surgical planning of patients with brain tumors. Neuroimage Clin (2016) 11:378-87. doi:10.1016/j.nicl.2016.03.003

53. Lee MH, Miller-Thomas MM, Benzinger TL, Marcus DS, Hacker CD, Leuthardt EC, et al. Clinical resting-state fMRI in the preoperative setting: are we ready for prime time? Top Magn Reson Imaging (2016) 25(1):11-8. doi:10.1097/RMR.0000000000000075

54. Sair HI, Yahyavi-Firouz-Abadi N, Calhoun VD, Airan RD, Agarwal S, Intrapiromkul J, et al. Presurgical brain mapping of the language network in patients with brain tumors using resting-state fMRI: comparison with task fMRI. Hum Brain Mapp (2016) 37(3):913-23. doi:10.1002/hbm.23075

55. Tie Y, Rigolo L, Norton IH, Huang RY, Wu W, Orringer D, et al. Defining language networks from resting-state fMRI for surgical planning - a feasibility study. Hum Brain Mapp (2014) 35(3):1018-30. doi:10.1002/hbm.22231

56. Dumoulin SO, Fracasso A, van der Zwaag W, Siero JCW, Petridou N. Ultrahigh field MRI: advancing systems neuroscience towards mesoscopic human brain function. Neuroimage (2017). doi:10.1016/j.neuroimage.2017.01.028

57. Kim M, Kim HS. Emerging techniques in brain tumor imaging: what radiologists need to know. Korean J Radiol (2016) 17(5):598-619. doi:10.3348/ kjr.2016.17.5.598

58. Cha S, Lupo JM, Chen MH, Lamborn KR, McDermott MW, Berger MS, et al. Differentiation of glioblastoma multiforme and single brain metastasis by peak height and percentage of signal intensity recovery derived from dynamic susceptibility-weighted contrast-enhanced perfusion MR imaging. AJNR Am J Neuroradiol (2007) 28(6):1078-84. doi:10.3174/ajnr.A0484

59. Calli C, Kitis O, Yunten N, Yurtseven T, Islekel S, Akalin T. Perfusion and diffusion MR imaging in enhancing malignant cerebral tumors. Eur J Radiol (2006) 58(3):394-403. doi:10.1016/j.ejrad.2005.12.032

60. Liao W, Liu Y, Wang X, Jiang X, Tang B, Fang J, et al. Differentiation of primary central nervous system lymphoma and high-grade glioma with dynamic susceptibility contrast-enhanced perfusion magnetic resonance imaging. Acta Radiol (2009) 50(2):217-25. doi:10.1080/02841850802616752

61. Toh $\mathrm{CH}$, Wei KC, Chang CN, Ng SH, Wong HF. Differentiation of primary central nervous system lymphomas and glioblastomas: comparisons of diagnostic performance of dynamic susceptibility contrast-enhanced perfusion MR imaging without and with contrast-leakage correction. AJNR Am J Neuroradiol (2013) 34(6):1145-9. doi:10.3174/ajnr.A3383

62. Mangla R, Kolar B, Zhu T, Zhong J, Almast J, Ekholm S. Percentage signal recovery derived from $M R$ dynamic susceptibility contrast imaging is useful to differentiate common enhancing malignant lesions of the brain. AJNR Am J Neuroradiol (2011) 32(6):1004-10. doi:10.3174/ajnr.A2441

63. Hourani R, Brant LJ, Rizk T, Weingart JD, Barker PB, Horská ACP. Can proton MR spectroscopic and perfusion imaging differentiate between neoplastic and nonneoplastic brain lesions in adults? AJNR Am J Neuroradiol (2008) 29(2):366-72. doi:10.3174/ajnr.A0810

64. Arvinda HR, Kesavadas C, Sarma PS, Thomas B, Radhakrishnan VV, Gupta $\mathrm{AK}$, et al. Glioma grading: sensitivity, specificity, positive and negative predictive values of diffusion and perfusion imaging. J Neurooncol (2009) 94(1):87-96. doi:10.1007/s11060-009-9807-6

65. Law M, Yang S, Wang H, Babb JS, Johnson G, Cha S, et al. Glioma grading: sensitivity, specificity, and predictive values of perfusion MR imaging and proton MR spectroscopic imaging compared with conventional MR imaging. AJNR Am J Neuroradiol (2003) 24(10):1989-98.
66. Shin JH, Lee HK, Kwun BD, Kim JS, Kang W, Choi CG, et al. Using relative cerebral blood flow and volume to evaluate the histopathologic grade of cerebral gliomas: preliminary results. AJR Am J Roentgenol (2002) 179(3):783-9. doi:10.2214/ajr.179.3.1790783

67. Patankar TF, Haroon HA, Mills SJ, Balériaux D, Buckley DL, Parker GJ, et al. Is volume transfer coefficient ( $\mathrm{K}(\operatorname{trans}))$ related to histologic grade in human gliomas? AJNR Am J Neuroradiol (2005) 26(10):2455-65.

68. Zhang N, Zhang L, Qiu B, Meng L, Wang X, Hou BL. Correlation of volume transfer coefficient Ktrans with histopathologic grades of gliomas. J Magn Reson Imaging (2012) 36(2):355-63. doi:10.1002/jmri.23675

69. Santarosa C, Castellano A, Conte GM, Cadioli M, Iadanza A, Terreni MR, et al. Dynamic contrast-enhanced and dynamic susceptibility contrast perfusion MR imaging for glioma grading: preliminary comparison of vessel compartment and permeability parameters using hotspot and histogram analysis. Eur J Radiol (2016) 85(6):1147-56. doi:10.1016/j.ejrad.2016. 03.020

70. Hilario A, Ramos A, Perez-Nuñez A, Salvador E, Millan JM, Lagares A, et al. The added value of apparent diffusion coefficient to cerebral blood volume in the preoperative grading of diffuse gliomas. AJNR Am J Neuroradiol (2012) 33(4):701-7. doi:10.3174/ajnr.A2846

71. Danchaivijitr N, Waldman AD, Tozer DJ, Benton CE, Brasil Caseiras G, Tofts PS, et al. Low-grade gliomas: do changes in rCBV measurements at longitudinal perfusion-weighted MR imaging predict malignant transformation? Radiology (2008) 247(1):170-8. doi:10.1148/radiol.2471062089

72. Barajas RF, Phillips JJ, Parvataneni R, Molinaro A, Essock-Burns E, Bourne $G$, et al. Regional variation in histopathologic features of tumor specimens from treatment-naive glioblastoma correlates with anatomic and physiologic MR Imaging. Neuro Oncol (2012) 14(7):942-54. doi:10.1093/ neuonc/nos128

73. Cha S, Knopp EA, Johnson G, Wetzel SG, Litt AW, Zagzag D. Intracranial mass lesions: dynamic contrast-enhanced susceptibility-weighted echoplanar perfusion MR imaging. Radiology (2002) 223(1):11-29. doi:10.1148/ radiol.2231010594

74. Lefranc M, Monet P, Desenclos C, Peltier J, Fichten A, Toussaint P, et al. Perfusion MRI as a neurosurgical tool for improved targeting in stereotactic tumor biopsies. Stereotact Funct Neurosurg (2012) 90(4):240-7. doi:10.1159/000338092

75. Bonekamp D, Deike K, Wiestler B, Wick W, Bendszus M, Radbruch A, et al. Association of overall survival in patients with newly diagnosed glioblastoma with contrast-enhanced perfusion MRI: comparison of intraindividually matched T1 and T2 (*)-based bolus techniques. J Magn Reson Imaging (2015) 42(1):87-96. doi:10.1002/jmri.24756

76. Hirai T, Murakami R, Nakamura H, Kitajima M, Fukuoka H, Sasao A, et al. Prognostic value of perfusion MR imaging of high-grade astrocytomas: long-term follow-up study. AJNR Am J Neuroradiol (2008) 29(8):1505-10. doi:10.3174/ajnr.A1121

77. Jain R, Poisson L, Narang J, Gutman D, Scarpace L, Hwang SN, et al. Genomic mapping and survival prediction in glioblastoma: molecular subclassification strengthened by hemodynamic imaging biomarkers. Radiology (2013) 267(1):212-20. doi:10.1148/radiol.12120846

78. Nakamura H, Murakami R, Hirai T, Kitajima M, Yamashita Y. Can MRIderived factors predict the survival in glioblastoma patients treated with postoperative chemoradiation therapy? Acta Radiol (2013) 54(2):214-20. doi:10.1258/ar.2012.120525

79. Saraswathy S, Crawford FW, Lamborn KR, Pirzkall A, Chang S, Cha S, et al. Evaluation of MR markers that predict survival in patients with newly diagnosed GBM prior to adjuvant therapy. J Neurooncol (2009) 91(1):69-81. doi:10.1007/s11060-008-9685-3

80. Pope WB, Qiao XJ, Kim HJ, Lai A, Nghiemphu P, Xue X, et al. Apparent diffusion coefficient histogram analysis stratifies progression-free and overall survival in patients with recurrent GBM treated with bevacizumab: a multi-center study. J Neurooncol (2012) 108(3):491-8. doi:10.1007/ s11060-012-0847-y

81. Pope WB, Lai A, Mehta R, Kim HJ, Qiao J, Young JR, et al. Apparent diffusion coefficient histogram analysis stratifies progression-free survival in newly diagnosed bevacizumab-treated glioblastoma. AJNR Am J Neuroradiol (2011) 32(5):882-9. doi:10.3174/ajnr.A2385

82. Burth S, Kickingereder P, Eidel O, Tichy D, Bonekamp D, Weberling L, et al. Clinical parameters outweigh diffusion- and perfusion-derived MRI 
parameters in predicting survival in newly diagnosed glioblastoma. Neuro Oncol (2016) 18(12):1673-9. doi:10.1093/neuonc/now122

83. Mangla R, Singh G, Ziegelitz D, Milano MT, Korones DN, Zhong J, et al. Changes in relative cerebral blood volume 1 month after radiationtemozolomide therapy can help predict overall survival in patients with glioblastoma. Radiology (2010) 256(2):575-84. doi:10.1148/radiol.10091440

84. Choi SH, Jung SC, Kim KW, Lee JY, Choi Y, Park SH, et al. Perfusion MRI as the predictive/prognostic and pharmacodynamic biomarkers in recurrent malignant glioma treated with bevacizumab: a systematic review and a timeto-event meta-analysis. J Neurooncol (2016) 128(2):185-94. doi:10.1007/ s11060-016-2102-4

85. Artzi M, Bokstein F, Blumenthal DT, Aizenstein O, Liberman G, Corn BW, et al. Differentiation between vasogenic-edema versus tumor-infiltrative area in patients with glioblastoma during bevacizumab therapy: a longitudinal MRI study. Eur J Radiol (2014) 83(7):1250-6. doi:10.1016/j.ejrad.2014.03.026

86. Artzi M, Blumenthal DT, Bokstein F, Nadav G, Liberman G, Aizenstein O, et al. Classification of tumor area using combined DCE and DSC MRI in patients with glioblastoma. J Neurooncol (2015) 121(2):349-57. doi:10.1007/ s11060-014-1639-3

87. Rahman R, Hamdan A, Zweifler R, Jiang H, Norden AD, Reardon DA, et al. Histogram analysis of apparent diffusion coefficient within enhancing and nonenhancing tumor volumes in recurrent glioblastoma patients treated with bevacizumab. J Neurooncol (2014) 119(1):149-58. doi:10.1007/ s11060-014-1464-8

88. Khayal IS, Polley MY, Jalbert L, Elkhaled A, Chang SM, Cha S, et al. Evaluation of diffusion parameters as early biomarkers of disease progression in glioblastoma multiforme. Neuro Oncol (2010) 12(9):908-16. doi:10.1093/ neuonc/noq049

89. Patel P, Baradaran H, Delgado D, Askin G, Christos P, Tsiouris AJ, et al. MR perfusion-weighted imaging in the evaluation of high-grade gliomas after treatment: a systematic review and meta-analysis. Neuro Oncol (2017) 19(1):118-27. doi:10.1093/neuonc/now148

90. Barajas RF, Chang JS, Segal MR, Parsa AT, McDermott MW, Berger MS, et al. Differentiation of recurrent glioblastoma multiforme from radiation necrosis after external beam radiation therapy with dynamic susceptibility-weighted contrast-enhanced perfusion MR imaging. Radiology (2009) 253(2):486-96. doi:10.1148/radiol.2532090007

91. Cha J, Kim ST, Kim HJ, Kim BJ, Kim YK, Lee JY, et al. Differentiation of tumor progression from pseudoprogression in patients with posttreatment glioblastoma using multiparametric histogram analysis. AJNR Am J Neuroradiol (2014) 35(7):1309-17. doi:10.3174/ajnr.A3876

92. Park JE, Kim HS, Goh MJ, Kim SJ, Kim JH. Pseudoprogression in patients with glioblastoma: assessment by using volume-weighted voxel-based multiparametric clustering of $\mathrm{mr}$ imaging data in an independent test set. Radiology (2015) 275(3):792-802. doi:10.1148/radiol.14141414

93. Prager AJ, Martinez N, Beal K, Omuro A, Zhang Z, Young RJ. Diffusion and perfusion MRI to differentiate treatment-related changes including pseudoprogression from recurrent tumors in high-grade gliomas with histopathologic evidence. AJNR Am J Neuroradiol (2015) 36(5):877-85. doi:10.3174/ajnr.A4218
94. Song YS, Choi SH, Park CK, Yi KS, Lee WJ, Yun TJ, et al. True progression versus pseudoprogression in the treatment of glioblastomas: a comparison study of normalized cerebral blood volume and apparent diffusion coefficient by histogram analysis. Korean J Radiol (2013) 14(4):662-72. doi:10.3348/ kjr.2013.14.4.662

95. Kong DS, Kim ST, Kim EH, Lim DH, Kim WS, Suh YL, et al. Diagnostic dilemma of pseudoprogression in the treatment of newly diagnosed glioblastomas: the role of assessing relative cerebral blood flow volume and oxygen-6-methylguanine-DNA methyltransferase promoter methylation status. AJNR Am J Neuroradiol (2011) 32(2):382-7. doi:10.3174/ajnr.A2286

96. Thomas AA, Arevalo-Perez J, Kaley T, Lyo J, Peck KK, Shi W, et al. Dynamic contrast enhanced T1 MRI perfusion differentiates pseudoprogression from recurrent glioblastoma. J Neurooncol (2015) 125(1):183-90. doi:10.1007/ s11060-015-1893-z

97. Suh CH, Kim HS, Choi YJ, Kim N, Kim SJ. Prediction of pseudoprogression in patients with glioblastomas using the initial and final area under the curves ratio derived from dynamic contrast-enhanced T1-weighted perfusion MR imaging. AJNR Am J Neuroradiol (2013) 34(12):2278-86. doi:10.3174/ajnr. A3634

98. Hein PA, Eskey CJ, Dunn JF, Hug EB. Diffusion-weighted imaging in the follow-up of treated high-grade gliomas: tumor recurrence versus radiation injury. AJNR Am J Neuroradiol (2004) 25(2):201-9.

99. Lee WJ, Choi SH, Park CK, Yi KS, Kim TM, Lee SH, et al. Diffusion-weighted MR imaging for the differentiation of true progression from pseudoprogression following concomitant radiotherapy with temozolomide in patients with newly diagnosed high-grade gliomas. Acad Radiol (2012) 19(11):1353-61. doi:10.1016/j.acra.2012.06.011

100. Yoo RE, Choi SH. Recent application of advanced MR imaging to predict pseudoprogression in high-grade glioma patients. Magn Reson Med Sci (2016) 15(2):165-77. doi:10.2463/mrms.rev.2015-0053

101. Kim HS, Goh MJ, Kim N, Choi CG, Kim SJ, Kim JH. Which combination of MR imaging modalities is best for predicting recurrent glioblastoma? Study of diagnostic accuracy and reproducibility. Radiology (2014) 273(3):831-43. doi:10.1148/radiol.14132868

102. Gill BJ, Pisapia DJ, Malone HR, Goldstein H, Lei L, Sonabend A, et al. MRI-localized biopsies reveal subtype-specific differences in molecular and cellular composition at the margins of glioblastoma. Proc Natl Acad Sci U S A (2014) 111(34):12550-5. doi:10.1073/pnas.1405839111

Conflict of Interest Statement: The authors declare that the research was conducted in the absence of any commercial or financial relationships that could be construed as a potential conflict of interest.

Copyright (๔ 2018 Salama, Heier, Patel, Ramakrishna, Magge and Tsiouris. This is an open-access article distributed under the terms of the Creative Commons Attribution License (CC BY). The use, distribution or reproduction in other forums is permitted, provided the original author(s) or licensor are credited and that the original publication in this journal is cited, in accordance with accepted academic practice. No use, distribution or reproduction is permitted which does not comply with these terms. 